\title{
CEsifo \\ WORKING

\section{The Covid-19 Pandemic and the Degree of Persistence of US Stock Prices and Bond Yields}

Guglielmo Maria Caporale, Luis Alberiko Gil-Alana, Carlos Poza 


\section{Impressum:}

CESifo Working Papers

ISSN 2364-1428 (electronic version)

Publisher and distributor: Munich Society for the Promotion of Economic Research - CESifo

$\mathrm{GmbH}$

The international platform of Ludwigs-Maximilians University's Center for Economic Studies and the ifo Institute

Poschingerstr. 5, 81679 Munich, Germany

Telephone +49 (0)89 2180-2740, Telefax+49 (0)89 2180-17845, email office@cesifo.de

Editor: Clemens Fuest

https://www.cesifo.org/en/wp

An electronic version of the paper may be downloaded

- from the SSRN website: www.SSRN.com

- from the RePEc website: $\quad$ www.RePEc.org

- from the CESifo website: https://www.cesifo.org/en/wp 


\title{
The Covid-19 Pandemic and the Degree of Persistence of US Stock Prices and Bond Yields
}

\begin{abstract}
This paper analyses the possible effects of the Covid-19 pandemic on the degree of persistence of US monthly stock prices and bond yields using fractional integration techniques. The model is estimated first over the period January 1966-December 2020 and then a recursive approach is taken to examine whether or not persistence has changed during the following pandemic period. We find that the unit root hypothesis cannot be rejected for stock prices while for bond yields the results differ depending on the maturity date and the specification of the error term. In general, bond yields appear to be more persistent, although there is evidence of mean reversion in case of 1 -year yields under the assumption of autocorrelated errors. The recursive analysis shows no impact of the Covid-19 pandemic on the persistence of stock prices, whilst there is an increase in the case of both 10- and 1- year bond yields but not of their spread.
\end{abstract}

JEL-Codes: C220, G100.

Keywords: stock market prices, US bonds, persistence, fractional integration, Covid-19.

Guglielmo Maria Caporale*

Department of Economics and Finance

Brunel University

United Kingdom - London, UB8 3PH

Guglielmo.Maria.Caporale@brunel.ac.uk

\author{
Luis Alberiko Gil-Alana \\ University of Navarra \\ Pamplona / Spain \\ alana@unav.es
}

\author{
Carlos Poza \\ Universidad Francisco de Vitoria \\ Madrid / Spain
}

*corresponding author

March 2021

Prof. Luis A. Gil-Alana gratefully acknowledges financial support from the MINEIC-AEIFEDERECO2017-85503-R project from 'Ministerio de Economía, Industria y Competitividad' (MINEIC), ‘Agencia Estatal de Investigación' (AEI) Spain and 'Fondo Europeo de Desarrollo Regional' (FEDER). He also acknowledges support from an internal Project of the Universidad Francisco de Vitoria. 


\section{Introduction}

The Covid-19 pandemic is a global health crisis that has had a devastating impact on economies worldwide as a result of lockdowns and other measures adopted to contain the spread of Coronavirus. Although previous pandemics such as the SARS (Severe Acute Respiratory Syndrome) outbreak had also had economic consequences (see, e.g., Chen et al., 2007, 2009) the current crisis has had unprecedented effects, being a combination of both supply and demand shocks that have required prompt and extensive policy measures (see Caporale and Cerrato, 2020). In addition to the real economy, financial markets have also been hit by the great degree of uncertainty generated by this crisis (see Baker et al., 2020). There exist already a few studies providing some preliminary evidence of their quick response to the Covid-19 outbreak and the resulting concerns about future economic prospects (see, e.g., Ramelli and Wagner, 2020 for the impact on various stock markets and Al-Awadhi et al., 2020, specifically for the Chinese case).

The present paper focuses on the US case and analyses the possible effects of the Covid-19 pandemic on the degree of persistence of both US monthly stock prices and bond yields. The adopted framework is based on the concept of fractional integration and is more general and flexible than the standard one which is characterised by the classical dichotomy between stationary $\mathrm{I}(0)$ and non-stationary $\mathrm{I}(1)$ series since it allows the difference parameter to take fractional as well as integer values. The model is estimated first over the period from January 1966 to December 2019 to obtain a measure of the degree of persistence of the series of interest prior to the Covid-19 outbreak. Then a recursive approach is taken to examine whether or not this has changed during the pandemic period.

The layout of the paper is as follows. Section 2 briefly reviews the relevant literature on US financial markets. Section 3 outlines the methodology. Section 4 
describes the data and presents the empirical results. Section 5 offers some concluding remarks.

\section{Literature Review}

Stock prices are some of the most frequently analysed economic series (see Granger, 1992). A variety of approaches have been followed in the literature. For instance, Wang et al. (2010) applied an interacting stochastic systems framework and built a model based on the random continuum percolation to investigate the "herd effect" in investor behaviour. Hedayati et al. (2016) used instead artificial neural networks (ANNs) to forecast the daily NASDAQ; specifically, they trained feedforward ANNs through backpropagation algorithms.

Atsalakis and Valavanis (2009) modelled stock prices by means of a neuro-fuzzy system including an Adaptive Neuro Fuzzy Inference System (ANFIS) controller; they showed that this method provides better forecasts than rival ones and represents a challenge for the weak form of the Efficient Market Hypothesis (EMH). Schotman et al. (2008) studied the implications of asset return predictability for long-term portfolio choices when return-forecasting variables are fractionally integrated; they estimated orders of integration of approximately 0.8 for key predictors, such as the dividend-price ratio and interest rates, and thus a higher long-term risk for stocks and bonds compared to the estimates obtained from a stationary VAR.

Most recently, a few studies have examined specifically the impact of the Covid19 pandemic on financial markets. For instance, Salisu and Vo (2020) evaluated the importance of health-news trends to forecast stock returns for a list of countries with high incidence of Covid-19; their results showed that a model incorporating a health-news index outperforms the benchmark historical average model; in addition, including 
macroeconomic factors and financial news improves the forecasting performance of the health news-based model. Štifanić et al. (2020) studied instead the effects of Covid-19 on Crude Oil price and three US stock indices: DJI, S\&P 500, and NASDAQ Composite; their approach to forecasting commodity and stock prices integrates the stationary wavelet transform (SWT) and bidirectional long short-term memory (BDLSTM) networks.

Bond markets and yield curves (and spreads) have also been extensively investigated because of their ability to anticipate macroeconomic trends. As pointed out by Andersen (2018), they contain timely information to gauge investors' expectations and reaction functions concerning policy decisions, with the yield curve providing a measure of market expectations about monetary policy, economic activity, and inflation.

This literature has developed considerably over the last few decades since the well-known paper due to Campbell (1986), who put forward a simple exchange model based on a general univariate stochastic process, stationary and invertible in levels or first differences, and discussed its implications for asset pricing. For example, Diebold et al. (2005) showed that a combined macro-finance modelling strategy provides a better understanding of the term structure of interest rates and in particular of the Nelson-Siegel and affine no-arbitrage term structure models. Diebold and Li (2006) used variants on the Nelson-Siegel exponential components framework to model the yield curve; they showed that the three time-varying parameters may be interpreted as factors corresponding to the level, slope, and curvature respectively, and estimated autoregressive models for the factors to generate short- and long-term forecasts. Demirel and Unal (2020) analysed 203 local bonds in the emerging markets of Indonesia, Brazil, India, South Africa, Mexico, and Turkey from a portfolio risk perspective; specifically, they estimated fractional models for risk evaluation. 
Other studies focus on asset price volatility. As highlighted by Dräger et al. (2020), the degree of long memory in stock market volatility can be interpreted as a measure of uncertainty: high degrees of long memory imply a low degree of uncertainty. Caporale et al. (2018) studied the degree of persistence of market fear as measured by the VIX index from 2004 to 2016 and found that its properties vary over time: in normal periods it exhibits anti-persistence, whereas during recession persistence increases. Hiremath and Bandi (2010) obtained evidence of long memory in volatility in the case of the Indian stock market using the fractionally integrated generalized autoregressive conditional heteroscedasticity (FIGARCH) model, which is shown to capture more accurately the persistence in volatility than the conventional ARCH-GARCH models. The same conclusions have been also reached by Christensen and Nielsen (2007) and Kasman and Torun (2007) for other markets. Martens et al. (2004) used instead a nonlinear Autoregressive Fractionally Integrated Moving Average (ARFIMA) model to analyse volatility in the S\&P500 stock index.

\section{Methodology}

Our modelling approach is based on the concept of fractional integration and is more general than the standard framework that only allows for integer degrees of differentiation. Specifically, a time series $x_{t}$ is said to be integrated of order $d$ or $I(d)$ if it can be represented as:

$$
(1-B)^{d} x_{t}=u_{t}, \quad t=1,2, \ldots,
$$

where $\mathrm{B}$ is the backshift operator, and $\mathrm{u}_{\mathrm{t}}$ exhibits short-memory, is integrated of order 0 (I(0)) and follows a white noise or weakly autocorrelated (e.g., ARMA) process. If $\mathrm{d}>0$ in (1) then $x_{t}$ is said to be a long-memory process since the autocorrelations decay hyperbolically, and the higher the value of $d$ is, the slower is the rate of decay. 
In our empirical analysis we also allow for a linear time trend and consider the following general specification:

$$
y_{t}=\alpha+\beta t+x_{t}, \quad t=1,2, \ldots,
$$

where $\mathrm{y}_{\mathrm{t}}$ stands for the series of interest, $\mathrm{x}_{\mathrm{t}}$ is the error term, and $\alpha$ and $\beta$ are unknown parameters to be estimated, respectively a constant and the coefficient on the linear time trend. The estimation is based on the Whittle function in the frequency domain and follows a testing procedure developed by Robinson (1994) which is most appropriate in the case of nonstationary series such as those analysed in this paper.

\section{Data and Empirical Results}

We examine four seasonally unadjusted US stock market indices (NYSE, NASDAQ 100, S\&P500, and Dow Jones) as well as US 10-year and 1-year Treasury bond yields and their spread (measured in percentage points); the series are monthly and the sample period goes from January 1966 to January 2021, therefore the total number of observations in each case is 661 . The chosen time span includes the last 8 NBER-dated recessions (NBER, 2021). The data source is Thomson Reuters Eikon.

Our objective is to analyse the possible impact of the Covid-19 pandemic on the parameter $\mathrm{d}$, which is a measure of persistence, for both stock prices and bond yields; therefore, as a first step we estimate the model up to December 2019 (namely, immediately before the start of the pandemic), and then use recursive methods to investigate the evolution of d from January 2020 onwards (namely, during the pandemic). Table 1 displays the estimates of $d$ and the corresponding 95\% confidence bands in the case of stock prices for the sample period ending in December 2019; we consider three possible specifications: i) no deterministic terms, ii) an intercept only, and iii) an intercept and a linear time trend. We also assume that the error term, i.e., $\mathrm{u}_{\mathrm{t}}$ in (1), is a white noise 
(panel i), a weakly autocorrelated process as in the non-parametric model of Bloomfield (panel ii), and finally, given the monthly frequency of the series, a seasonal monthly AR(1) process (panel iii). The best model is chosen on the basis of the statistical significance of the estimated coefficients as indicated by their t-statistics. As can be seen, the time trend is required in all cases and the $\mathrm{I}(1)$ hypothesis cannot be rejected in any case - in other words, the three series are highly persistent and shocks have permanent effects.

\section{[Insert Table 1 about here]}

Next we re-estimate the differencing parameter recursively adding one observation (month) at a time. The results based on the autocorrelation model of Bloomfield (1973) for the errors are displayed in Figure 1 (those based on the assumption of a white noise process for the errors are broadly similar and are not reported to save space). It can be seen that this parameter is relatively stable around 1 throughout the Covid-19 period, which implies that the degree of persistence of stock prices has not been affected by the pandemic.

\section{[Insert Figure 1 about here]}

Table 2 reports the estimation results over the period up to December 2019 for bond yields and their spread. The same three specifications are estimated as for stock prices. The best model for both yield series includes the intercept only, whilst no deterministic terms are required in the case of the spread. The orders of integration are slightly higher than for stocks; specifically, there is evidence of $I(d)$ with $d>1$ for the two yield series under the assumptions of white noise and seasonal AR(1) errors; the I(1) hypothesis cannot be rejected for 10-year yields when assuming autocorrelation in the errors as in the model of Bloomfield (1973), whilst it is rejected in favour of mean reversion (i.e., $d<1$ ) in the case of 1 -year yields. Thus, it appears that bonds behave 
differently depending on their maturity. Figure 2 displays the recursive estimates of $d$ (again for the case of Bloomfield errors) over the pandemic period. It can be seen that, unlike the case of stock prices, the degree of persistence of bond yields appears to have been affected by the Covid-19 pandemic. In particular, the estimated parameter $\mathrm{d}$ increases from around 1 to values significantly above 1 in the case of 10-year bond yields; by contrast, the estimated values of $\mathrm{d}$ are still significantly below 1 for 1 -year bond yields (which implies mean reversion), and the increase in this parameter occurs a few months later. Finally, all values are significantly above 1 in the case of the spread but there is not much evidence of an increase in d over time.

\section{[Insert Table 2 and Figure 2 about here]}

\section{Conclusions}

This paper analyses the possible effects of the Covid-19 pandemic on the degree of persistence of both US monthly stock prices and bond yields using fractional integration techniques. The model is estimated first over the period January 1966-December 2020 to obtain a measure of the degree of persistence of the series of interest prior to the Covid19 outbreak. Then a recursive approach is taken to examine whether or not this has changed during the pandemic period.

We find that the unit root hypothesis cannot be rejected for stock prices while for bond yields the results differ depending on the maturity date and the specification of the error term. In general, bond yields appear to be more persistent, although there is evidence of mean reversion in case of 1-year yields under the assumption of autocorrelated errors. Further, the recursive analysis shows no impact of the Covid-19 pandemic on the persistence of stock prices, whilst there is an increase in the case of both 10- and 1- year yields but not of their spread. 
On the whole, our findings point to a greater degree of market efficiency in the case of stock prices, which appear to be unpredictable since they exhibit a unit root and thus follow a random walk - unlike bond yields, for which there is evidence of some predictability. Volatility persistence is a further important issue to be investigated in future work given the high degree of uncertainty generated by the Covid-19 pandemic (see Baker et al., 2020). 


\section{References}

Al-Awadhi, A.M., Alsaifi, K., Al-Awadhi, A., and Alhammadi, S. (2020). Death and contagious infectious diseases: impact of the COVID-10 virus on stock market returns. Journal of Behavioral and Experimental Finance, 27.

Andersen, N. (2018). Yield curve modelling and a conceptual framework for estimating yield curves: evidence from the European Central Bank's yield curves. European Central Bank Statistics Paper Series No 27 / February 2018.

Atsalakis, G., and Valavanis, K.P. (2009). Forecasting stock market short-term trends using a neuro-fuzzy based methodology. Expert Systems with Applications, Volume 36, Issue 7, Pages 10696-10707. https://doi.org/10.1016/j.eswa.2009.02.043.

Baker, S. R., Bloom, N., Davis, S.J., Kost, K., Sammon, M. and T. Viratyosin. (2020): "The Unprecedented Stock Market Reaction to COVID-19", available at https://nbloom.people.stanford.edu/research.

Bloomfield, P. (1973). An exponential model in the spectrum of a scalar time series, Biometrika, 60, 217-226.

Campbell, J.Y. (1986). Bond and stock returns in a simple exchange model. Quarterly Journal of Economics, 101(4): 785-803.

Caporale, G.M. and M. Cerrato (2020), "The COVID-19 pandemic and the economy: We are fighting a new war", Policy Scotland, 21 May 2020, available at https://policyscotland.gla.ac.uk/covid-19-pandemic-and-the-economy-we-are-fightinga-new-war/

Caporale, G.M., Gil-Alana, L.A., and Plastun, A. (2018). Is market fear persistent? A long-memory analysis. Finance Research Letters, Volume 27, Pages 140-147, https://doi.org/10.1016/j.frl.2018.02.007.

Chen, C.D., Chen, C.C., Tang, W.W., and B.Y. Huang (2009), "The positive and negative impacts of the SARS outbreak: A case of the Taiwan industries", Journal of Development Areas, 43, 1, 281-293.

Chen, M.H., Jang, S.S., and W.G. Kim (2007), "The impact of the SARS outbreak on Taiwanese hotel stock performance: an event-study approach", International Journal of Hospital Management, 26, 1, 200-212.

Christensen, B.J. and Nielsen, M.O. (2007). The Review of Economics and Statistics. Vol. 89, No. 4, pp. 684-700. The MIT Press.

Demirel, M. and Unal, G. (2020). Applying multivariate-fractionally integrated volatility analysis on emerging market bond portfolios. Financial Innovation 6, 50. https://doi.org/10.1186/s40854-020-00203-3

Diebold, F.X., and Li, C. (2006). Forecasting the term structure of government bond yields. Journal of Econometrics, Volume 130, Issue 2, Pages 337-364. https://doi.org/10.1016/j.jeconom.2005.03.005. 
Diebold, F.X., Piazzesi, M., and Rudebusch, G.D. (2005). Modeling Bond Yields in Finance and Macroeconomics. Working Paper Series 2005-04. Federal Reserve Bank of San Francisco, USA.

Dräger, L., Nguyen, D.B.B., Prokopczuk, M., and Sibbertsen, P. (2020). The Long Memory of Equity Volatility and the Macroeconomy: International Evidence. Hannover Economic Papers (HEP) dp-667, Leibniz Universität Hannover, Wirtschaftswissenschaftliche Fakultät.

Granger, C.W.J. (1992). Forecasting stock market prices: Lessons for forecasters. International Journal of Forecasting 8, 3-13. Elsevier Science Publishers.

Hedayati Moghaddam, A., Hedayati Moghaddam, M., and Esfandyari, M. (2016). Stock market index prediction using artificial neural network. Journal of Economics, Finance and Administrative Science. Volume 21, Issue 41, Pages 89-93. https://doi.org/10.1016/j.jefas.2016.07.002.

Hiremath, G.S. and Bandi, K. (2010). Long Memory in Stock Market Volatility: Evidence from India. Artha Vijnana, Vol. 52, No. 4, pp. 332-345.

Kasman, A. and Torun, E. (2007). Long Memory in the Turkish Stock Market Return and Volatility. Central Bank Review, 2. Pages 13-27.

Martens, M., Van Dijk, D., and de Pooter, M. (2004). Modeling and Forecasting S\&P 500 Volatility: Long Memory, Structural Breaks and Nonlinearity. Tinbergen Institute Discussion Papers 04-067/4, Tinbergen Institute.

Ramelli, S. and Wagner, A. (2020), "What the stock market tells us about the consequences of COVID-19", in R. Baldwin and B. Weder di Mauro (eds.), Mitigating the COVID Economic Crisis: Act Fast and Do Whatever It Takes, A VoxEU.org Book, CEPR Press.

Robinson, P.M. (1994) Efficient tests of nonstationary hypotheses, Journal of the American Statistical Association 89, 1420-1437.

Salisu, A.A., and Vo, X.V. (2020). Predicting stock returns in the presence of COVID-19 pandemic: The role of health news. International Review of Financial Analysis, 71. https://doi.org/10.1016/j.irfa.2020.101546

Schotman, P.C., Tschernig, R., and Budek, J. (2008). Long Memory and the Term Structure of Risk. Journal of Financial Econometrics, Volume 6, Issue 4, Fall 2008, Pages 459-495, https://doi.org/10.1093/jifinec/nbn010

Štifanić, D., Musulin, J., Miočević, A., Šegota, S.B., Šubić, R., and Car, Z. (2020). Impact of COVID-19 on Forecasting Stock Prices: An Integration of Stationary Wavelet Transform and Bidirectional Long Short-Term Memory. Complexity, Vol. 2020, Article ID 1846926. https://doi.org/10.1155/2020/1846926 
Wang, J., Wang, Q., Shao, J. (2010). Fluctuations of stock price model by statistical physics systems. Mathematical and Computer Modelling, Volume 51, Issues 5-6, Pages 431-440. https://doi.org/10.1016/j.mcm.2009.12.003. 
Table 1: Estimates of d: Stock indices. Sample period: January 1966-December 2019

\begin{tabular}{|c|c|c|c|}
\hline Series & No terms & An intercept & $\begin{array}{l}\text { An intercept and a } \\
\text { linear time trend }\end{array}$ \\
\hline \multicolumn{4}{|c|}{ i) White noise } \\
\hline Dow Jones & $0.99(0.93,1.05)$ & $1.00 \quad(0.95,1.07)$ & $1.00 \quad(0.95,1.07)$ \\
\hline NYSE & $0.99(0.94,1.05)$ & $1.03(0.97,1.09)$ & $1.03 \quad(0.97,1.09)$ \\
\hline Standard \& Poor & $0.99(0.94,1.06)$ & $1.02(0.96,1.08)$ & $1.02(0.96,1.08)$ \\
\hline \multicolumn{4}{|c|}{ ii) Autocorrelation (Bloomfield) } \\
\hline Dow Jones & $0.98 \quad(0.87,1.08)$ & $0.98 \quad(0.91,1.07)$ & $0.98(0.91,1.08)$ \\
\hline NYSE & $0.98 \quad(0.89,1.08)$ & $0.96(0.88,1.05)$ & $0.96(0.87,1.05)$ \\
\hline Standard \& Poor & $0.98 \quad(0.90,1.09)$ & $0.98 \quad(0.91,1.08)$ & $0.98(0.91,1.08)$ \\
\hline \multicolumn{4}{|c|}{ iii) Seasonal monthly AR } \\
\hline Dow Jones & $0.99(0.93,1.05)$ & $1.00 \quad(0.95,1.07)$ & $1.00 \quad(0.95,1.07)$ \\
\hline NYSE & $0.99(0.93,1.06)$ & $1.03(0.97,1.09)$ & $1.03(0.97,1.10)$ \\
\hline Standard \& Poor & $0.99(0.93,1.05)$ & $1.02(0.96,1.08)$ & $1.02(0.96,1.08)$ \\
\hline
\end{tabular}

The values in parentheses are the $95 \%$ confidence intervals for the non-rejection values of $\mathrm{d}$. In bold, the selected specification on the basis of the statistical significance of the deterministic terms. 
Figure 1: Recursive estimates of $d$ from January 2020 to February 2021. Stock indices

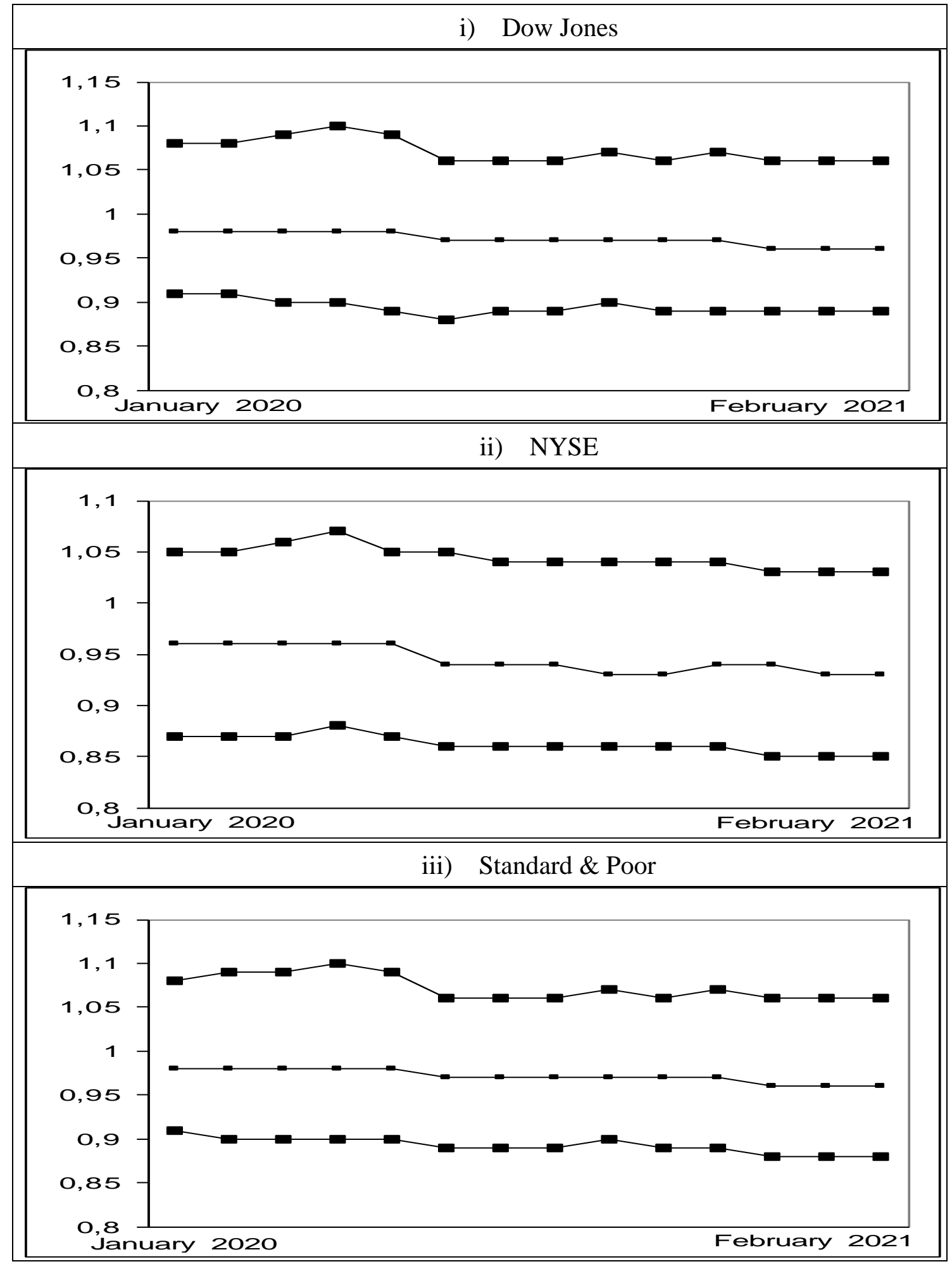


Table 2: Estimates of d: Bond yields. Sample period: January 1966-December 2019

\begin{tabular}{|c|c|c|c|}
\hline Series & No terms & An intercept & $\begin{array}{l}\text { An intercept and a } \\
\text { linear time trend }\end{array}$ \\
\hline \multicolumn{4}{|c|}{ i) White noise } \\
\hline TY -10 & $1.04(0.99,1.10)$ & $1.19(1.13,1.26)$ & $1.19(1.13,1.26)$ \\
\hline $\mathrm{TY}-1$ & $1.01(0.96,1.08)$ & $1.14(1.06,1.24)$ & $1.14(1.06,1.24)$ \\
\hline Spread & $1.22(1.16,1.29)$ & $1.22(1.16,1.29)$ & $1.22(1.16,1.29)$ \\
\hline \multicolumn{4}{|c|}{ ii) Autocorrelation (Bloomfield) } \\
\hline TY - 10 & $1.01(0.94,1.09)$ & $1.02(0.95,1.10)$ & $1.02(0.95,1.10)$ \\
\hline $\mathrm{TY}-1$ & $0.98 \quad(0.90,1.07)$ & $0.87 \quad(0.79,0.96)$ & $0.86(0.78,0.96)$ \\
\hline Spread & $1.09(1.02,1.19)$ & $1.09(1.02,1.19)$ & $1.09(1.02,1.19)$ \\
\hline \multicolumn{4}{|c|}{ iii) Seasonal monthly AR } \\
\hline Dow Jones & $1.04(0.98,1.10)$ & $1.18(1.12,1.26)$ & $1.18(1.12,1.26)$ \\
\hline NYSE & $1.01(0.96,1.08)$ & $1.14(1.06,1.23)$ & $1.14(1.06,1.23)$ \\
\hline Standard \& Poor & $1.21(1.16,1.28)$ & $1.21(1.16,1.28)$ & $1.21 \quad(1.16,1.28)$ \\
\hline
\end{tabular}

The values in parentheses are the $95 \%$ confidence intervals for the non-rejection values of $\mathrm{d}$. In bold, the selected specification on the basis of the statistical significance of the deterministic terms. 
Figure 2: Recursive estimates of $d$ from January 2020 to February 2021. Bond yields

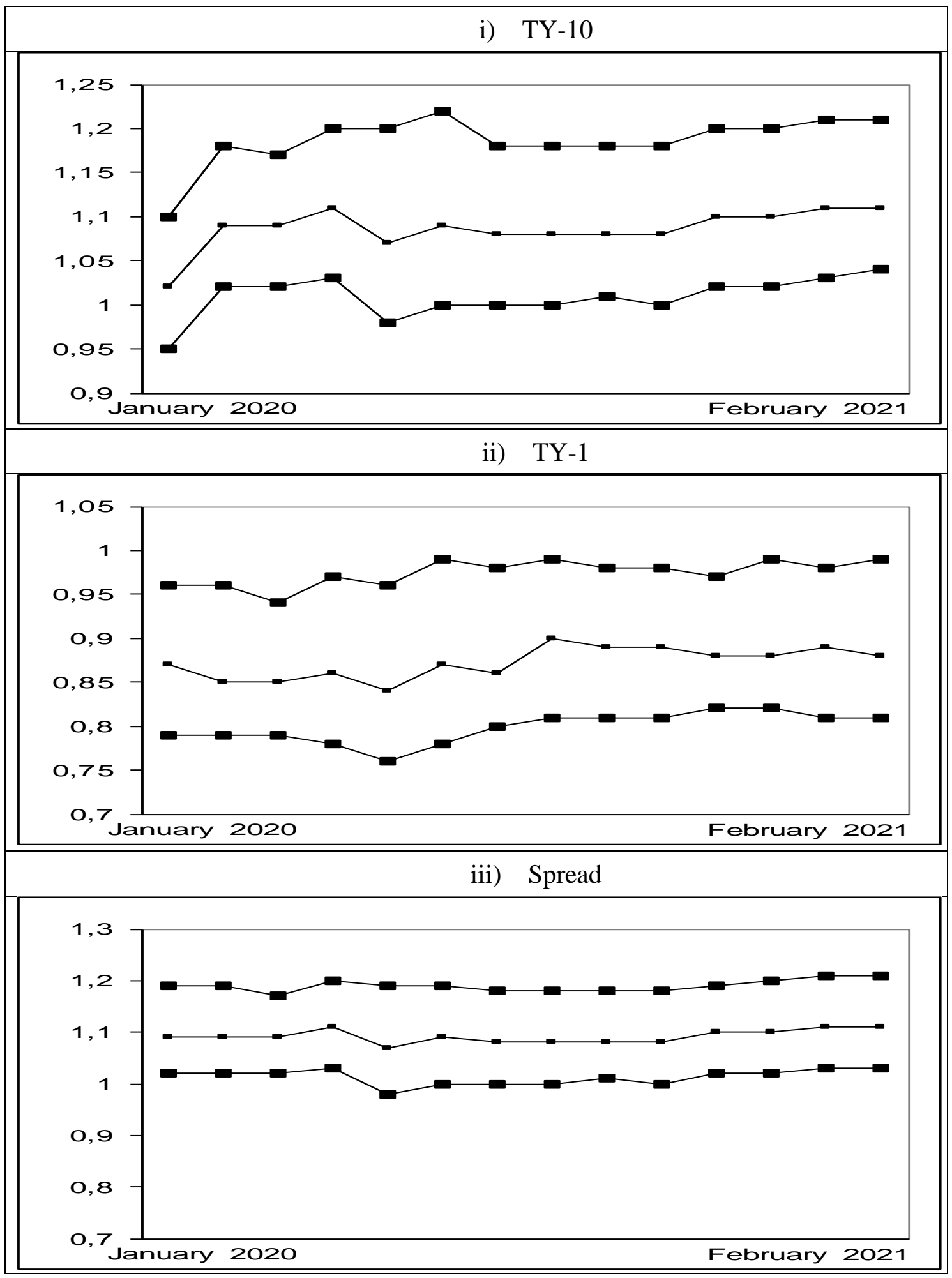

